\title{
Basal insulin therapy may reduce the risk of new-onset diabetes after renal transplantation
}

A dministration of basal insulin therapy to renal transplant recipients in the immediate posttransplantation phase might reduce their risk of new-onset diabetes after transplantation (NODAT), say researchers.

Hyperglycemia is common after renal transplantation in previously nondiabetic patients, and is a predictor of subsequent NODAT development. No effective interventions are available to reduce the risk of NODAT, which is associated with reduced graft and patient survival. Previous studies have shown that transient insulin therapy is effective for the treatment of hyperglycemia, improves $\beta$-cell function, and improves long-term glycemic control in patients with newly diagnosed type 2 diabetes. Hecking et al. therefore initiated the 12-month TIP (Treat-to-Target Trial of Basal Insulin in Post-Transplant Hyperglycemia) study to investigate whether basal insulin therapy might be effective in controlling postoperative hyperglycemia in previously nondiabetic patients, and whether it might lower the risk of NODAT by giving longterm $\beta$-cell protection. "The TIP study is the first in a series of projects on NODAT that my research group started in 2008," explains Marcus Säemann, corresponding author on the study.

The researchers randomly assigned 56 renal transplant recipients (without a history of diabetes) to either basal insulin during the immediate posttransplantation phase (treatment group) or standard-of-care (control group). The treatment group initially received morning doses of isophane insulin at $6 \mathrm{IU}, 8 \mathrm{IU}$ or $10 \mathrm{IU}$, if their blood glucose level was $\geq 8 \mathrm{mmol} / \mathrm{l}, \geq 10 \mathrm{mmol} / \mathrm{l}$ or $\geq 13 \mathrm{mmol} / \mathrm{l}$, respectively, on the previous evening. Insulin was subsequently uptitrated; the normoglycemic goal was 6.1-6.7 mmol/1. Control patients were managed with conventional antidiabetic and antihyperglycemic agents; treatment was not encouraged at blood glucose levels

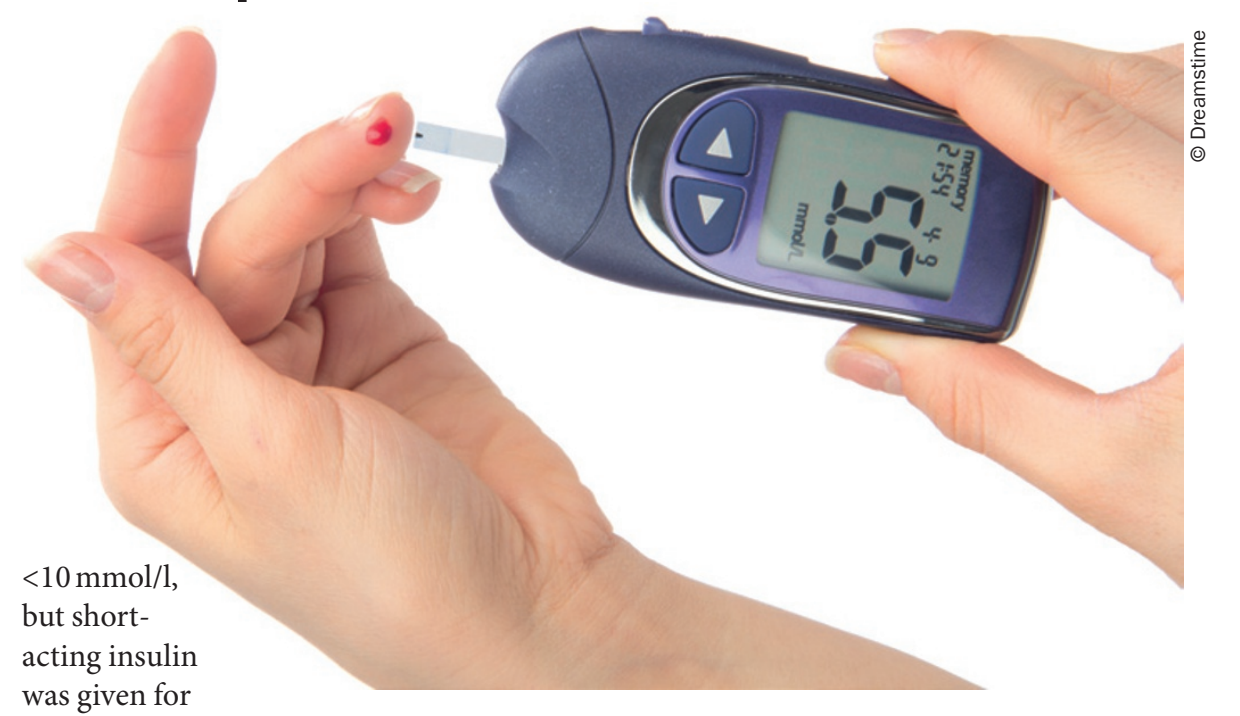

severe hyperglycemia (blood glucose $\geq 14 \mathrm{mmol} / \mathrm{l}$ ). Data from 50 patients -25 in each group-were available for analysis.

All 25 patients in the treatment group had blood glucose levels $\geq 8 \mathrm{mmol} / \mathrm{l}$ by the end of the second day after transplantation, and received basal insulin therapy the following morning. In the control group, 23 of 25 patients had a blood glucose level $\geq 11 \mathrm{mmol} / \mathrm{l}$ at least once, and 18 patients required shortacting insulin. Average daily glucose levels were lower and average insulin doses were higher in the treatment group than in the control group. Hypoglycemic episodes occurred five times in the treatment group and once in the control group.

The odds of developing NODAT was lower in the treatment group than in the control group (odds ratio 0.27 ) by 12 months post-transplantation. The primary end point, hemoglobin A1c $\left(\mathrm{HbA}_{1 \mathrm{c}}\right)$ level 3 months after transplantation, was significantly lower in the treatment group. Thereafter, $\mathrm{HbA}_{1 \mathrm{c}}$ remained at the same level through 12 months in the treatment group, despite a weaning of insulin therapy after $\sim 100$ days. "This result indicates a long-lasting and robust therapeutic effect," states Säemann. One year after transplantation, all treatment group whereas seven of 25 control patients needed antidiabetic agents. Insulin sensitivity did not differ between groups, but $\beta$-cell function was better in the treatment group throughout the study.

"An NIH-sponsored study, ITPNODAT (Insulin Therapy for the Prevention of New-Onset Diabetes after Transplantation), will start enrolling patients at six international transplant centers in 2012," notes Säemann. "We will also be starting a prospective study employing the latest technology with insulin pumps to further optimize glycemic control in our transplant patients in order to decrease the occurrence of diabetes after transplantation. If this and future studies yield similar results, clinical practice may change towards the routine administration of insulin treatment after transplantation."

\section{Rebecca Ireland}

\footnotetext{
Original article Hecking, M. et al. Early basal insulin therapy decreases new-onset diabetes after renal transplantation. J.Am. Soc. Nephrol. doi:10.1681/ ASN.2011080835

Further reading Sharif, A. \& Baboolal, K. Complications associated with new-onset diabetes after kidney transplantation. Nat. Rev. Nephrol. 8, 34-42 (2012)
} patients were insulin-independent, 